\title{
Metabolomic Study of Chardonnay Grapevines Double Stressed with Esca-Associated Fungi and Drought
}

\author{
Marta R. M. Lima, Antoinette F. Machado, and Walter D. Gubler
}

University of California Davis, Department of Plant Pathology, One Shields Avenue, Hutchison Hall, Davis 95616. Accepted for publication 18 February 2017.

\begin{abstract}
Esca is a complex grapevine trunk disease associated with fungal infection of the xylem. However, the inconstancy of external symptoms and the ability of esca-associated fungi to inhabit grapevines without causing apparent disease suggests that abiotic factors might be involved in the disease. Water stress has been proposed to be one of the factors influencing esca symptom manifestation but the specific role played by water stress on esca development is unknown. We conducted a proton nuclear magnetic resonance spectroscopy-based metabolomic study aiming at unveiling drought-induced modifications in xylem sap composition that could contribute to esca-related infection progression. Vitis vinifera 'Chardonnay' plants were inoculated with

Phaeomoniella chlamydospora or Phaeoacremonium minimum and exposed to water stress. Using this approach, 28 metabolites were identified in xylem sap. The results show that water stress induces a concentration increase of most metabolites in xylem sap. An average increase $>100 \%$ was found for asparagine, isoleucine, leucine, methionine, phenylalanine, proline, tyrosine, valine, sarcosine, and trigonelline. The increase of these compounds seems to be also modulated by fungal infection. This study offers further support to the putative role of drought in esca expression, and opens new avenues of research by extending the current knowledge about metabolites possibly involved in esca disease.
\end{abstract}

Trunk diseases are among the most destructive diseases of grapevine. Esca (also called black measles, young grapevine decline, or apoplexy) is a complex trunk disease affecting grapevines worldwide. This disease, along with other grapevine trunk diseases, has significant economic impact in regions where viticulture is an important activity, having an estimated worldwide annual cost in excess of U.S.\$ 1.5 billion, solely for replanting vines (Hofstetter et al. 2012). Several aspects contribute to the economic burden of esca, mainly: (i) esca-related infection can be found at all stages of vine culture, including nursery materials, young plants, and mature vines (Bertsch et al. 2013; Fontaine et al. 2016; Surico et al. 2006); (ii) esca diagnosis is difficult, most often being diagnosed only when leaf or berry symptoms become visible at a late infection stage (Feliciano et al. 2004; Kuntzmann et al. 2010); and (iii) presently, there is no effective treatment for esca (Bertsch et al. 2013). Hence, the disease leads to costs related to decreased production, lower quality of berries, and, ultimately, labor and material cost for the uprooting and replanting of vines (Calzarano et al. 2001, 2004; Eskalen et al. 2007; Hofstetter et al. 2012; Lorrain et al. 2012; Marchi 2001; Surico et al. 2000).

In its most severe form (named apoplexy), esca causes sudden dieback of grapevine shoots, leaf drop, and shriveling of grape clusters, many times culminating with plant death (Bertsch et al. 2013; Mugnai et al. 1999). In its chronic form, esca is characterized by external symptoms in leaves and berries. Leaf symptoms appear as chlorotic spots expanding between the veins, eventually forming a "tiger-stripe" pattern. Berry symptoms are evident as dark spots on the berry skin, which is why the disease is also known as black measles (Bertsch et al. 2013; Mugnai et al. 1999). It has been reported that physiological alterations (namely, a reduction in photosynthesis and decrease of photosynthetic pigments) occur in

Corresponding author: W. D. Gubler; E-mail address: wdgubler@ucdavis.edu

*The $\boldsymbol{e}$-Xtra logo stands for "electronic extra" and indicates that one supplementary figure and one supplementary table are published online.

(c) 2017 The American Phytopathological Society leaves before symptom appearance, and these alterations become more serious as the symptoms progress (Fontaine et al. 2016; Letousey et al. 2010; Magnin-Robert et al. 2011; Petit et al. 2006; Valtaud et al. 2011). Though the etiology of esca is not fully understood, it has been recognized that the xylem-inhabiting fungi Phaeomoniella chlamydospora and Phaeoacremonium minimum play a role as causal agents of the disease (Bertsch et al. 2013; Mugnai et al. 1999; Surico et al. 2006). These fungi cause internal symptoms in the trunk and shoots, appearing as black streaks along xylem vessels (Bertsch et al. 2013; Larignon and Dubos 1997; Mugnai et al. 1999). Nonetheless, these fungi are known to live in grapevines for several years without causing apparent disease (Bruez et al. 2014, 2016). Mugnai et al. (1999) proposed that symptoms in leaves and berries might be caused by fungal toxins translocated to the leaves via xylem sap. In fact, several fungal toxins (mainly scytalone, isosclerone, and other naphtalenones) were isolated from Phaeomoniella chlamydospora and Phaeoacremonium minimum cultures (Abou-Mansour et al. 2004; Andolfi et al. 2011; Tabacchi et al. 2000), and in vitro assays showed the ability of these toxins to produce esca-like symptoms in detached leaves and berries (Bruno and Sparapano 2006a, 2007; Bruno et al. 2007). However, in vivo tests to reproduce esca external symptoms by inoculating vines with esca-related fungi have rarely been successful, suggesting that other factors, in addition to the fungi, contribute to disease manifestation (Surico et al. 2006). Indeed, the appearance of disease symptoms has been associated with climatic conditions (namely, related to precipitation) (Marchi et al. 2006; Surico et al. 2006), as well as with the occurrence of abiotic stress (in particular, water stress) (Ferreira et al. 1999). Moreover, an increase in esca-symptomatic vineyards has been noticed in California since the beginning of the current drought period in 2012 (W. D. Gubler, personal communication).

Some studies have suggested the association of water stress with symptom expression of other grapevine trunk diseases, such as those caused by Botryosphaeriaceae spp. and Eutypa lata (Sosnowski et al. 2011; van Niekerk et al. 2011). Few studies addressed the interaction of water stress and esca-related infection. Ferreira et al. (1999) found higher symptom expression in plants 
subjected to water stress, whereas Edwards et al. (2007b,c) describe that Phaeomoniella chlamydospora infection changes a vine's physiological response to water stress by interfering with normal stomatal regulation and lowering leaf water potential. However, it has been reported that esca infection and drought affect the functioning of photosystem II in different ways (Christen et al. 2007). Moreover, the growth of grapevines inoculated with Phaeomoniella chlamydospora and exposed to water stress was found to be significantly affected by water stress but not by fungal infection (Fischer and Kassemeyer 2012). Presently, the specific mechanism underlying the predisposition of water-stressed vines to the progression of esca-related infection is not known though, in general terms, the higher predisposition to disease has been attributed to the effects of drought on a plant's physiology that reduce its capacity to resist infection (Ayres 1984; Boyer 1995; Schoeneweiss 1978, 1981).

Modern metabolomic techniques are excellent tools to study the overall modifications induced by biotic or abiotic stresses in plants. Though targeted approaches, particularly aiming at phenolic compounds, have been used to study esca-induced chemical changes in several grapevine tissues, few untargeted metabolomic studies of esca disease have been done. Changes in phenolic compounds were reported for infected grapevine calli (Bruno and Sparapano 2006b), and an accumulation of several stilbene polyphenols, particularly resveratrol and $\varepsilon$-viniferin, was found in brown-red wood of escadiseased grapevines (Amalfitano et al. 2000, 2011). Additionally, the total amount of phenolics was found to increase in esca-diseased leaves, and specific compounds were shown to be highly correlated with disease (Lima et al. 2017). Changes in the phenolic component were also studied in green stems, cordons, and trunks of grape plants affected with esca, showing an increase of stilbene compounds in symptomatic woody tissues (Magnin-Robert et al. 2016). One untargeted study used proton nuclear magnetic resonance $\left({ }^{1} \mathrm{H}-\right.$ NMR) spectroscopy to study the influence of esca disease on the metabolome of grapevine leaves; this approach revealed a profound impact of esca on several metabolic pathways, with diseased leaves showing an increase in phenolic compounds together with a decrease in carbohydrates, suggesting that diseased leaves reroute carbon and energy from primary to secondary metabolism (Lima et al. 2010).

Though chemical composition of xylem sap is known to change upon infection with xylem-inhabiting microorganisms (Wallis and Chen 2012; Yadeta and Thomma 2013), the xylem sap was rarely addressed in respect to esca infection. Changes in the xylem have been studied before (Del Río et al. 2001, 2004; Edwards et al. 2007a; Gómez et al. 2016) but few studies concerning xylem sap exist. The studies on xylem sap have shown accumulation of fungal toxins and host phenolic compounds in sap of esca-diseased grapevines (Bruno and Sparapano 2006a, 2007; Bruno et al. 2007). Thus far, no comprehensive characterization of the metabolome of xylem sap of esca-infected plants has been attempted.

We hypothesize that drought induces modifications in xylem sap composition that could contribute to esca-related infection progression. In this study, we used a ${ }^{1} \mathrm{H}-\mathrm{NMR}$ spectroscopy metabolomic approach and a greenhouse model of esca early infection to analyze the impact of water stress on plant's growth; photosynthetic pigments; and xylem sap volume, $\mathrm{pH}$, and chemical composition.

\section{MATERIALS AND METHODS}

Plant material and growth conditions. Dormant cuttings of Vitis vinifera 'Chardonnay' were obtained from Foundation Plant Services (University of California-Davis [UCD]). The base of the cuttings was dipped in GardenTech RootBoost (TechPac LLC, Atlanta) before being planted in 25-cm-deep cones with a 1:1 mixture of perlite and UC soil mix (50\% washed sand and 50\% sphagnum peat moss). Cuttings were allowed to root for 5 weeks in a misting chamber. Rooted cuttings were transplanted into 7.5-liter pots with Agronomy UC soil mix (40\% washed sand, $20 \%$ sphagnum peat moss, $20 \%$ redwood compost, and $20 \%$ pumice rock) and transferred to a greenhouse at the UCD Orchard Park facilities. After 15 weeks, all plants had grown a shoot $1 \mathrm{~m}$ in length and were all at the same baseline size. Only one shoot at the two uppermost bud positions was allowed to grow; lower shoots were pruned. The last pruning occurred 2 days prior to fungal inoculation. No pruning was done after experimental treatments started. The experiment took place between July and October 2015. Days were 12 to $13 \mathrm{~h}$ long, with average temperature $25.6^{\circ} \mathrm{C}$ (minimum $16.7^{\circ} \mathrm{C}$ and maximum $35.6^{\circ} \mathrm{C}$ ) inside the greenhouse. Plants were dripline irrigated four times a day with Hoagland's solution $(33 \mathrm{ml} / \mathrm{min})$ for 4 min until plants reached baseline size, and for $8 \mathrm{~min}$ after that until the end of the experiment. At baseline size and without further pruning, the plants grew freely, therefore requiring the additional watering to remain unstressed.

Experimental treatments: fungal inoculation and water stress. After 15 weeks in the greenhouse (baseline), plants were randomized into one of six treatments using a random sequence generated at https://www.random.org/ $(n=6)$ : (i) mock inoculated, water stressed; (ii) mock inoculated, nonwater stressed; (iii) Phaeoacremonium minimum inoculated, water stressed; (iv) Phaeoacremonium minimum inoculated, nonwater stressed; (v) Phaeomoniella chlamydospora inoculated, water stressed; and (vi) Phaeomoniella chlamydospora inoculated, nonwater stressed (Supplementary Fig. S1). Fungal inoculation was performed and the infection was allowed to establish for 6 weeks before applying the concurrent water stress. For fungal inoculation, the stem of each plant was sanitized with $70 \%$ ethanol $3 \mathrm{~cm}$ below the growing shoot and a longitudinal $1 \mathrm{~cm}$ cut was made with a sterile scalpel blade to expose the xylem vessels. The xylem was inoculated with $50 \mu \mathrm{l}$ of the Phaeoacremonium minimum or Phaeomoniella chlamydospora spore solution $\left(4 \times 10^{3}\right.$ spores $\left./ \mathrm{ml}\right)$. Controls were mock inoculated with the same volume of sterile deionized water. The droplet was readily absorbed and the wound closed with Parafilm to avoid desiccation. Six weeks after inoculation, water stress was applied by disconnecting the plants from the irrigation driplines. The level of stress was monitored by measuring stem water potential within $1 \mathrm{~h}$ of solar noon, using a Sholander bomb (model 610; PMS Instrument Company, Albany, OR). The leaves were enclosed in a humidified plastic bag covered with aluminum foil, and left to equilibrate for 15 min before cutting the petiole (Secchi and Zwieniecki 2012). Water-stressed plants were kept at an interval of -1.6 to $-1.0 \mathrm{MPa}$ (achieved by intermittent watering events), whereas control plants were maintained at -0.6 to $-0.4 \mathrm{MPa}$ (achieved by keeping the plants connected to the dripline irrigation system for the entire period of the experiment). Stem water potential was measured frequently (four to six times per week) and, whenever the water potential of water-stressed plants was below $-1.6 \mathrm{MPa}$, the plants were reconnected to the irrigation driplines for a period of $24 \mathrm{~h}$. This prevented plants from entering a severe water stress level, allowing the plants to return to the desired moderate to high level of water stress.

Fungal isolates maintenance and inoculum preparation. Phaeomoniella chlamydospora and Phaeoacremonium minimum dried frozen cultures (isolates C25 and A54, respectively, previously shown to be virulent) were retrieved from our laboratory collection (UCD, Plant Pathology Department) and grown on Difco potato dextrose agar (Becton, Dickinson and Company, Sparks, MD) amended with $0.01 \%$ tetracycline (Amresco, Solon, OH) (PDA-Tet), at room temperature $\left(24 \pm 1{ }^{\circ} \mathrm{C}\right)$, being subcultured every 4 weeks. On the inoculation day, $5 \mathrm{ml}$ of sterile deionized water was added to 4-week-old plates and the surface of the fungal colonies was gently scraped with a dissecting needle to release spores. The resulting suspension was filtered through sterile fourlayer cheese cloth to remove debris and collected into a sterile $15-\mathrm{ml}$ conical centrifuge tube. Filtrate concentration was determined by counting spores under the microscope using a hemocytometer, and a fungal spore solution of $4 \times 10^{3} \mathrm{spores} / \mathrm{ml}$ was prepared for each fungal isolate. 
Sample harvest. Harvest of plant material took place in greenhouse $4 \mathrm{~h}$ after sunrise. Plant shoot growth above the baseline size was measured, and 6 to 10 leaves from each plant were collected, rinsed in deionized water, immediately frozen in liquid nitrogen, and stored at $-20^{\circ} \mathrm{C}$ until photosynthetic pigment analysis. For xylem sap collection, the base of the stem and the top of defoliated shoot were cut. At the base, $1 \mathrm{~cm}$ of the bark around the stem was removed to avoid phloem contamination, and the dissected part of the stem was connected through Tygon tubing to a $1.5-\mathrm{ml}$ microtube resting inside a vacuum chamber, as previously described (Secchi and Zwieniecki 2012). Vacuum was applied and small stem sections were cut from the top as the xylem sap was collected into the microtube (Secchi and Zwieniecki 2012). Stem sections and xylem sap were kept on ice until being transported to the lab. Stem sections were stored at $4^{\circ} \mathrm{C}$ overnight for fungal isolation. Sap $\mathrm{pH}$ was measured using an Accumet microelectrode (Fisher Scientific, Hampton, NH) connected to a SevenCompact $\mathrm{pH}$ meter (Mettler Toledo, Columbus, $\mathrm{OH}$ ). Xylem sap was filtered through Whatman PVDF $0.45-\mu$ m syringe filters (GE Healthcare Life Sciences, Pittsburgh), flash frozen in liquid nitrogen, and stored at $-20^{\circ} \mathrm{C}$ until further analysis.

Fungal isolation from inoculated plants. Xylem tissue surrounding the inoculation site of mock- and fungal-inoculated plants was collected under sterile conditions and plated on Petri dishes with PDA-Tet. Plates were kept at room temperature $\left(24 \pm 1^{\circ} \mathrm{C}\right)$ for 4 weeks. Phaeomoniella chlamydospora and Phaeoacremonium minimum were identified based on colony morphology. Identification was confirmed by analysis of internal transcribed spacer (ITS) region. Total DNA was extracted using the DNeasy Plant Minikit (Qiagen, Hilden, Germany), starting by homogenizing, with a micropestle, approximately $100 \mathrm{mg}$ of fungal tissue in the recommended amount of buffer AP1 and RNaseA. The next steps followed the manufacturer's "Plant tissue (mini protocol)" until the final elution in $100 \mu \mathrm{l}$ of included elution buffer $\mathrm{AE}(10 \mathrm{mM}$ Tris $\cdot \mathrm{Cl}, 0.5 \mathrm{mM}$ EDTA, pH 9.0). A polymerase chain reaction (PCR) was carried in $25 \mu \mathrm{l}$ of reaction volume with $2 \mu \mathrm{l}$ of the DNA eluate, $0.4 \mu \mathrm{M}$ primer ITS4, $0.4 \mu \mathrm{M}$ primer ITS5 (White et al. 1990), and $1 \times$ PCR master mix (Thermo Scientific, Waltham, MA). The PCR program consisted of a step at $94^{\circ} \mathrm{C}$ for $2 \mathrm{~min}$; followed by 35 cycles of $94^{\circ} \mathrm{C}$ for $1 \mathrm{~min}, 58^{\circ} \mathrm{C}$ for $1 \mathrm{~min}$, and $72^{\circ} \mathrm{C}$ for $1.5 \mathrm{~min}$; and a final extension step of $5 \mathrm{~min}$ at $72^{\circ} \mathrm{C}$. The PCR products were electrophoresed for $1 \mathrm{~h}$ at $120 \mathrm{~V}$ on a $2 \%$ agarose gel in $1 \times$ Trisacetate-EDTA buffer, with $1 \times$ SYBR Safe DNA Gel Stain (Invitrogen, Carlsbad, CA), along with a 100-bp DNA ladder (Thermo Scientific), to verify integrity and specificity of the amplified DNA fragment. The PCR product was purified using the QIAquick PCR Purification Kit (Qiagen), following the manufacturer's instructions, and sent for sequencing at the UCD Division of Biological Sciences sequencing facility. Sequences were processed using the software CodonCode Aligner (CodonCode Corporation, Centerville, MA) and compared with nucleotide sequences deposited in the National Center for Biotechnology Information GenBank using the MegaBLAST tool.

Photosynthetic pigments quantification. Frozen leaves were ground with a mortar and pestle in the presence of liquid nitrogen. Powdered leaf tissue (approximately $100 \mathrm{mg}$ ) was extracted in $10 \mathrm{ml}$ of cold acetone: $1 \mathrm{M}$ Tris- $\mathrm{HCl}$ (80:20 [vol/vol], pH 8) (Fisher Scientific; Mediatech Inc., Manassas, VA) (Sims and Gamon 2002). Samples were incubated at $4^{\circ} \mathrm{C}$ for $72 \mathrm{~h}$, with occasional shaking. Absorbance was recorded in a SmartSpec Plus spectrophotometer (Bio-Rad, Hercules, CA) at 470, 537, 647, and $663 \mathrm{~nm}$. Amount of carotenoids and chlorophylls a and b was calculated according to Sims and Gamon (2002).

Sample preparation and ${ }^{1} \mathrm{H}$-NMR spectroscopy analysis. Frozen xylem sap was thawed on ice and $10 \%$ (vol/vol) of $\mathrm{D}_{2} \mathrm{O}$ (Acros Organics, Fair Lawn, NJ), containing 0.1\% 3-(trimethylsilyl) propionic acid- $\mathrm{d}_{4}$ sodium salt $\left(\mathrm{TMSP}-\mathrm{d}_{4} ;\right.$ Acros Organics) as chemical shift reference, was added to a final volume of $200 \mu \mathrm{l}$. The sample was transferred into 3-mm NMR tubes (Bruker BioSpin Corp., Billerica, MA) and NMR spectra were acquired at the UCD
NMR facility on a 600-MHz Bruker AvanceIII Spectrometer equipped with a SampleJet automatic sample changer. Standard onedimensional spectra were acquired at $300 \mathrm{~K}$ using the "noesypr1d" pulse sequence with water presaturation during relaxation delay and mixing time. Acquired spectra consisted of 128 scans, with 65,000 complex data points and a spectral width of 7,211.539 Hz. Spectra were processed using Topspin (v3.5pl4; BrukerBioSpin Corp.). Before Fourier transformation, the free induction decays were zero-filled to 64,000 points and multiplied by a $0.3-\mathrm{Hz}$ line-broadening function. Spectra were phased- and baseline-corrected manually, and the chemical shifts referenced to the TMSP signal. Processed spectra were imported to the Chenomx NMR suite (v8.1; Chenomx Inc., Edmonton, Alberta, Canada) for targeted identification and quantification of metabolites present in xylem sap. Identification of compounds was also assisted by the literature (Evidente et al. 2000; Lima et al. 2014) and the human metabolome database (Wishart et al. 2013).

Data analysis. The experiment followed a completely randomized design, with six plants per group. During the experimental period, two mock-inoculated plants (one in the water-stressed and one in the nonwater-stressed group) died. Statistical analysis and plots were performed in R version 3.2.2 (R Core Team 2015), using car (Fox and Weisberg 2011), plyr (Wickham 2011), and ggplot2 (Wickham 2009) packages. Shapiro-Wilk and Leven's tests were performed to assess data normality and homoscedasticity. Two-way analysis of variance followed by Tukey's honestly significant difference test was used to test differences in plant growth, xylem sap volume, xylem sap $\mathrm{pH}$, and photosynthetic pigments. For metabolomic data, one Phaeoacremonium minimum-inoculated/waterstressed sample was removed as outlier, before testing significant differences using the Mann Whitney $U$ test, and Kruskal-Wallis test with Dunn's post hoc test using Bonferroni correction for multiple comparisons. Significance was considered at $P \leq 0.05$.

\section{RESULTS}

Fungal infection. At harvest, 3 months after fungal inoculation, black or dark-brown longitudinal lesions were seen inside the stem of plants inoculated with Phaeomoniella chlamydospora or Phaeoacremonium minimum (Fig. 1B and C), whereas no disease discoloration was seen in control plants (Fig. 1A). The necrosis spread along the entire length of the cut made to perform the inoculation $(1 \mathrm{~cm})$ and could be seen extending by 1 to $2 \mathrm{~mm}$ in the xylem beyond the margins of the cut (Fig. $1 \mathrm{~B}$ and $\mathrm{C}$ ). The aspect and size of the lesions were similar regardless of whether plants had been exposed to water stress or not. Phaeoacremonium minimum or Phaeomoniella chlamydospora were isolated from xylem tissue around the inoculation site in $100 \%$ of the plants inoculated with Phaeoacremonium minimum or Phaeomoniella chlamydospora, respectively. None of these fungi were recovered from any of

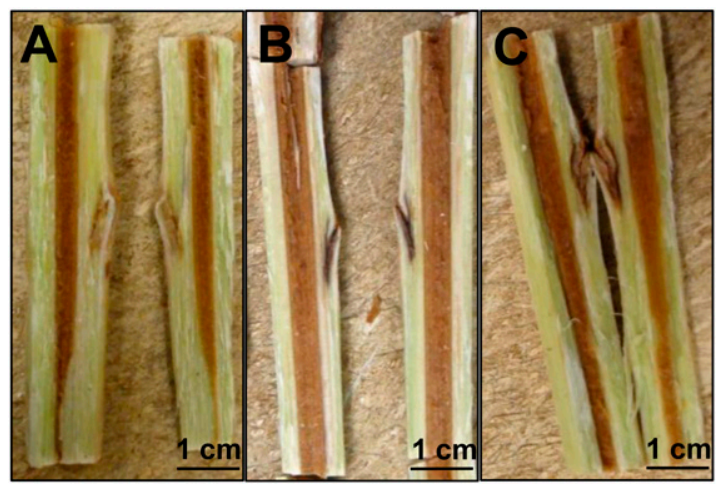

Fig. 1. Longitudinal trunk sections at infection point 3 months after inoculation. Typical esca black or dark-brown lesions visible at and around inoculation site on fungal inoculated plants. A, Mock (sterile water); B, Phaeomoniella chlamydospora; and $\mathbf{C}$, Phaeoacremonium minimum. 
control plants $(0 \%)$. The results indicate that a successful infection was established in xylem of fungal inoculated plants, though it was slow progressing. Nonetheless, at this early infection stage, no external leaf symptoms could be seen in any of the plants.

Assessment of combined fungal inoculation and water stress on plant growth, xylem sap volume and $\mathbf{p H}$, and leaf photosynthetic pigments. Plant growth above baseline level was evaluated at harvest. The results showed a marked decrease in plant growth in response to water stress (Fig. 2A). When fungal infection was present, a slight decrease in plant growth was seen compared
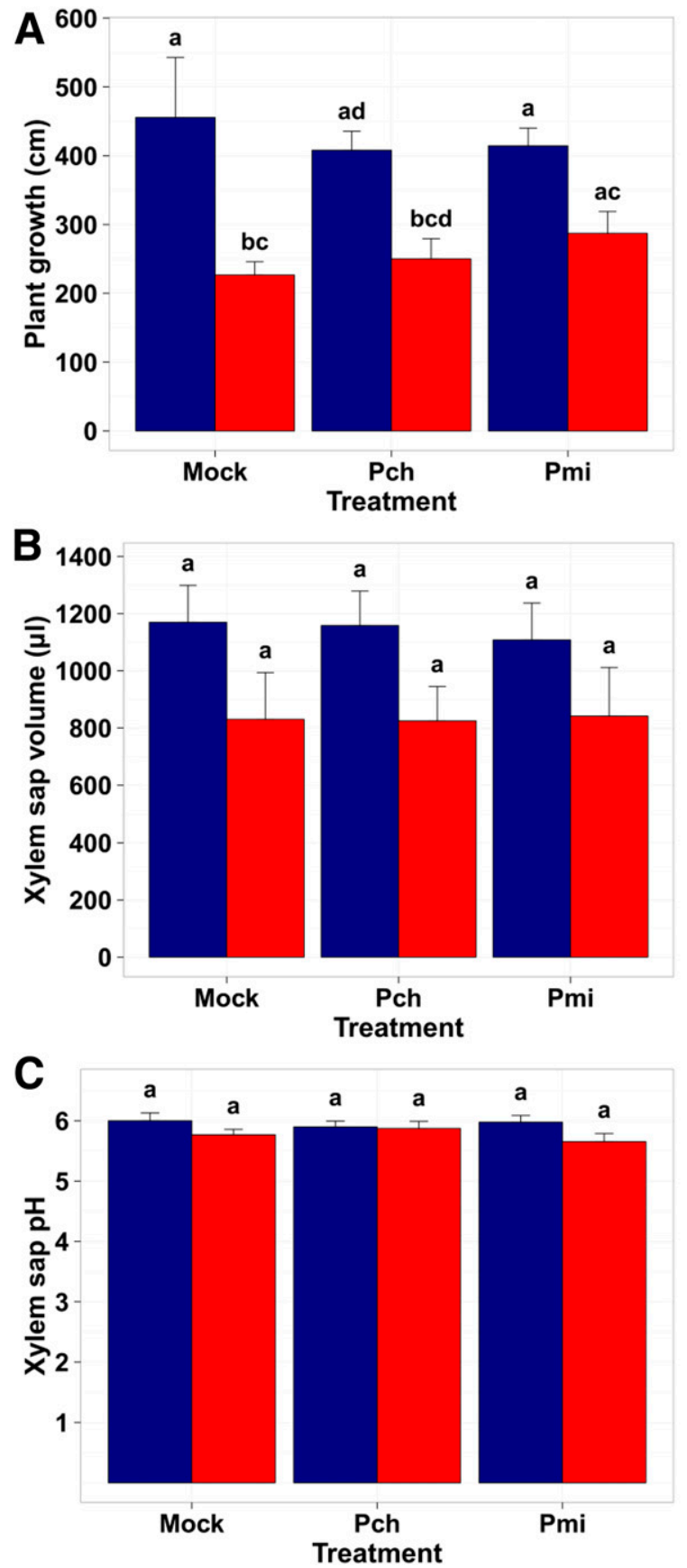

Fig. 2. Plant growth and xylem sap volume and $\mathrm{pH}$ of Vitis vinifera Chardonnay plants at harvest time. Rooted canes were grown in greenhouse for 15 weeks before inoculation: Mock $=$ sterile water Pch $=$ Phaeomoniella chlamydospora, and Pmi = Phaeoacremonium minimum . Six weeks after inoculation, plants were kept regularly watered (left column in each pair) or subjected to water stress (right column in each pair) for 7 weeks. A, Plant shoot growth (cm) above baseline size; $\mathbf{B}$, xylem sap volume $(\mu \mathrm{l})$; and $\mathbf{C}$, xylem sap $\mathrm{pH}$. Average \pm standard error. Treatment groups sharing the same letter are not significantly different (two-way analysis of variance, Tukey's honestly significant difference, $P<0.05$ ). with the noninoculated control but it was not statistically significant (Fig. 2A). Interestingly, the impact of water stress on growth of fungus-inoculated plants seems to be lower, which translated into a nonstatistically significant difference between water-stressed and nonwater-stressed plants when plants were inoculated with Phaeoacremonium minimum or Phaeomoniella chlamydospora (Fig. 2A).

The volume of xylem sap recovered from water-stressed plants was generally lower than the volume collected from nonwaterstressed plants (Fig. 2B), varying in treatment group average between 825 and $842 \mu \mathrm{l}$ under water stress and between 1,108 and
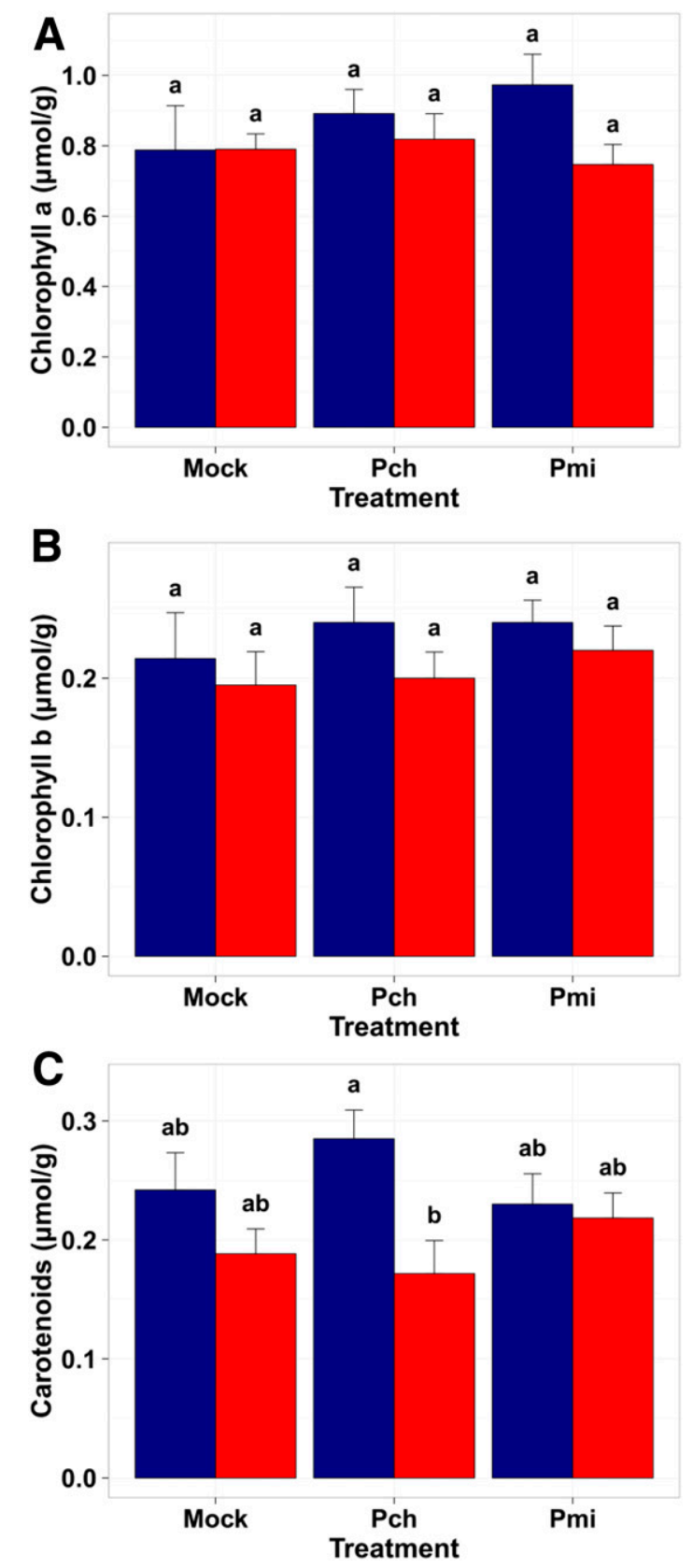

Fig. 3. Photosynthetic pigments in leaves of Vitis vinifera Chardonnay plants at harvest time. Rooted canes were grown in greenhouse for 15 weeks before inoculation: Mock = sterile water, Pch $=$ Phaeomoniella chlamydospora , and Pmi = Phaeoacremonium minimum . Six weeks after inoculation, plants were kept regularly watered (left column in each pair) or subjected to water stress (right column in each pair) for 7 weeks. A, Chlorophyll a $(\mu \mathrm{mol} / \mathrm{g}$ fresh weight); $\mathbf{B}$, chlorophyll b ( $\mu \mathrm{mol} / \mathrm{g}$ fresh weight); and $\mathbf{C}$, carotenoids $(\mu \mathrm{mol} / \mathrm{g}$ fresh weight). Average \pm standard error. Treatment groups sharing the same letter are not significantly different (two-way analysis of variance, Tukey's honestly significant difference, $P<0.05)$. 
$1,170 \mu \mathrm{l}$ in nonwater-stressed samples. The $\mathrm{pH}$ of water-stressed xylem sap was slightly lower (pH 5.7 to 5.9) than that of nonwaterstressed sap ( $\mathrm{pH} 5.9$ to 6.0), though the difference was not statistically significant (Fig. 2C). These differences in xylem sap pH were similar regardless of fungal inoculation.

Leaf chlorophyll a, chlorophyll b, and carotenoids were quantified. The amount of these pigments slightly decreased when plants were exposed to water stress (Fig. 3A to C). Carotenoids were significantly decreased in plants inoculated with Phaeomoniella chlamydospora and under water stress (Fig. 3C).

${ }^{1} \mathrm{H}$-NMR spectroscopy analysis of grapevine xylem sap. Representative ${ }^{1} \mathrm{H}-\mathrm{NMR}$ spectra of grapevine xylem sap are shown in Figure 4. The spectra of xylem sap of plants inoculated with either Phaeoacremonium minimum or Phaeomoniella chlamydospora were visually similar to those of mock (sterile water)-inoculated plants.
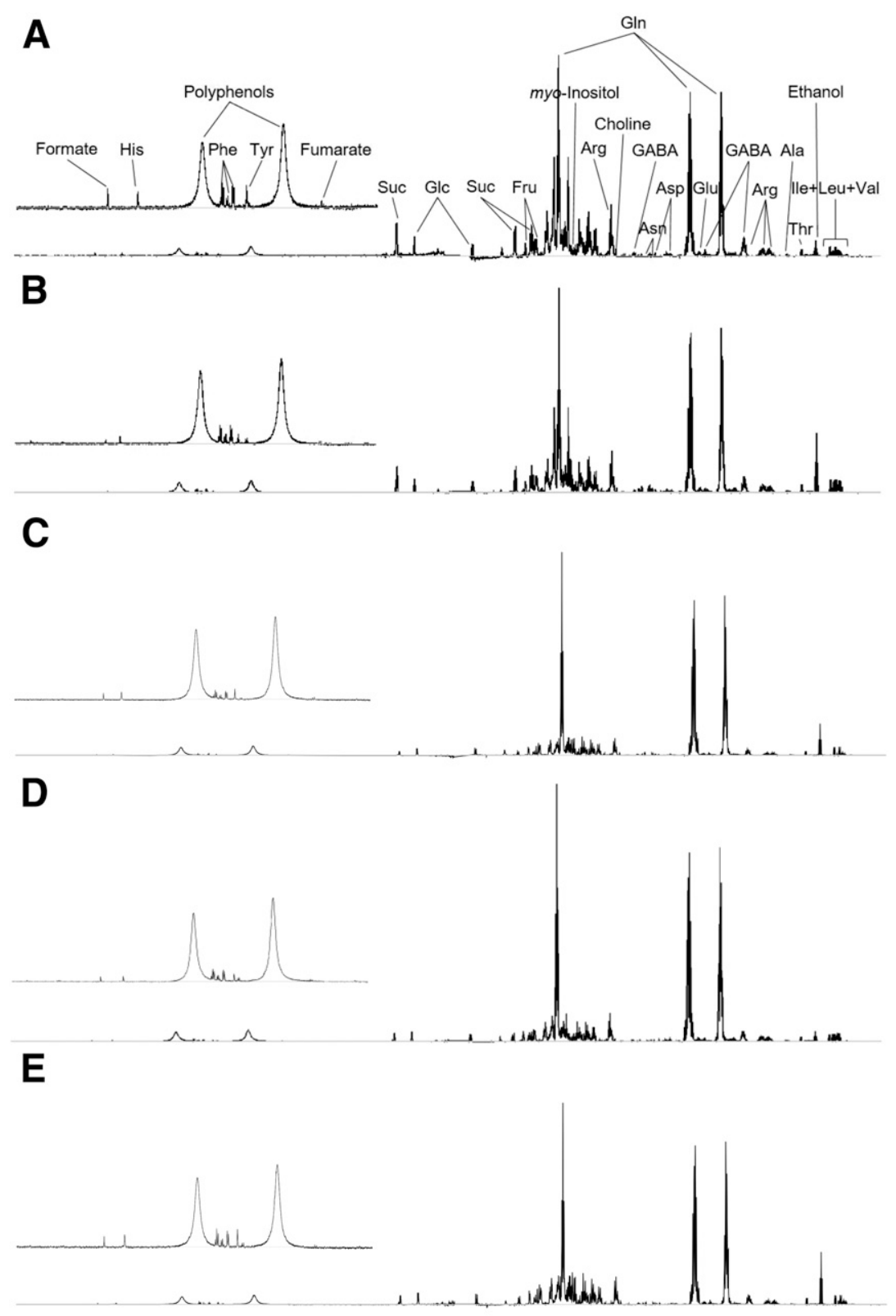

$\mathbf{F}$

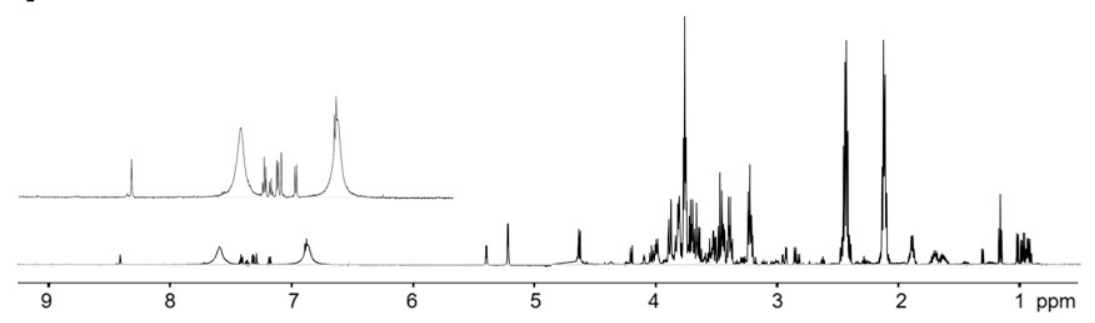

Fig. 4. Typical proton nuclear magnetic resonance spectra of grapevine xylem sap. Insets refer to the 6 to 9.25 ppm region. Assignment of major peaks indicated on top panel. A, Mock (sterile water), nonwater stress; B, mock (sterile water), water stress; C, Phaeomoniella chlamydospora, nonwater stress; D, Phaeomoniella chlamydospora, water stress; E, Phaeoacremonium minimum, nonwater stress; and F, Phaeoacremonium minimum, water stress. 
All major signals in the spectra of grapevine xylem sap were identified and are listed in Table 1. In total, 28 metabolites were identified, including amino acids (alanine, arginine, asparagine, aspartate, glutamate, glutamine, histidine, isoleucine, leucine, methionine, phenylalanine, proline, threonine, tyrosine, and valine), sugars (glucose, fructose, and sucrose), salt or ester forms of monoand dicarboxylic acids (formate and fumarate, respectively), alcohols (ethanol and methanol), and other small molecules (choline, 4aminobutyrate [GABA], myo-inositol, sarcosine, and trigonelline), as well as signals arising from polyphenols.

Additionally, the spectra were searched for signals characteristic of the mycotoxins associated with Phaeoacremonium minimum and Phaeomoniella chlamydospora (scytalone and isosclerone) but these fungal toxins were not detected in the xylem sap of inoculated vines.

Metabolite changes in xylem sap. The concentration of identified compounds in xylem sap was determined using Chenomx software. Average concentration of each metabolite is presented in Table 2, and boxplots in Figures 5 and 6 illustrate the variance in the data. Overall, the results indicate that an increase in the concentration of most metabolites was induced in xylem sap under water stress. This includes notable concentration increase of arginine, asparagine, aspartate, isoleucine, leucine, methionine, proline, tyrosine, sarcosine, and trigonelline, as well as minor concentration increase of phenylalanine, threonine, valine, glucose, sucrose, 4-aminobutyric acid, and myo-inositol (Figs. 5 and 6). The concentration of some amino acids (alanine, glutamate, glutamine, and histidine), formate, fumarate, ethanol, methanol, choline, and fructose seems to remain stable in xylem sap regardless of fungal inoculation or water stress (Figs. 5 and 6 ). Remarkable average concentration increase $>100 \%$ induced by water stress was found for asparagine, isoleucine, leucine, methionine, phenylalanine, proline, tyrosine, valine, sarcosine, and trigonelline (Table 2). It is noteworthy that the increase of these compounds in xylem sap was significantly $(P \leq 0.05)$ higher in xylem sap of plants inoculated with Phaeoacremonium minimum or Phaeomoniella chlamydospora (Figs. 5 and 6).

\section{DISCUSSION}

Water stress has been associated with the expression of esca disease but the mechanism by which drought influences the development of esca in grapevine is not fully understood. In this work, we assessed the impact of water stress on grapevines at an early stage of esca infection, aiming at unveiling the contribution of drought to the development of esca disease. Because esca is caused by xylem-inhabiting fungi, we focused on the xylem sap, because it constitutes the environment the fungi are exposed to.

The results show that our inoculation procedure was successful and fungal infection was achieved, which was evident by the presence of internal symptoms (Fig. 1) and the reisolation of either Phaeoacremonium minimum or Phaeomoniella chlamydospora from the margins of the lesions of the inoculated plants. However, no visible external symptoms could be seen at this early infection stage. This is consistent with field observations that infected plants develop symptoms long after initial infection (Bruez et al. 2014, 2016). Furthermore, our findings are in agreement with a previous greenhouse study conducted by Fischer and Kassemeyer (2012), in which internal but not external symptoms were found 10 months after inoculation with Phaeomoniella chlamydospora spores.

In the field, esca-affected plants are reported to have lower growth. However, in our greenhouse study, no significant differences were found in plant growth due to either Phaeoacremonium aleophilum or Phaeomoniella chlamydospora infection; however, significantly lower growth was registered in response to water stress (Fig. 2A). These results are in accordance with those of Fischer and Kassemeyer (2012). These authors inoculated plants with Phaeomoniella chlamydospora and subjected the plants to water stress; 10 months after inoculation, significantly lower shoot growth and lower aboveground weight were found in response to water stress but not in response to fungal infection (Fischer and Kassemeyer 2012). The decrease of vegetative growth of grapevines as a consequence of drought is well documented (Chaves et al. 2010; Lovisolo et al. 2010; Schultz and Matthews 1988; Stevens et al. 1995).

TABLE 1. Metabolites observed in proton nuclear magnetic resonance spectra of grapevine xylem sap

\begin{tabular}{|c|c|}
\hline Assignment $^{\mathrm{a}}$ & $\delta_{\mathrm{Hppm}}\left(\right.$ Multiplicity/J Hz) ${ }^{\mathrm{b}}$ \\
\hline 4-Aminobutyrate & $1.89(\mathrm{~m}), \mathbf{2 . 2 9}(\mathrm{t} / 7.4), 3.01(\mathrm{t} / 7.6)$ \\
\hline Alanine & $1.47(\mathrm{~d} / 7.2), 3.78(\mathrm{q})$ \\
\hline Arginine & $1.64(\mathrm{~m}), 1.71(\mathrm{~m}), 1.90(\mathrm{~m}), 3.23(\mathrm{t}), 3.77(\mathrm{t} / 6.2)$ \\
\hline Asparagine & $2.84(\mathrm{dd}), \mathbf{2 . 9 5}(\mathrm{dd}), 4.0(\mathrm{dd})$ \\
\hline Aspartate & $2.67(\mathrm{dd}), \mathbf{2 . 8 1}(\mathrm{dd}), 3.89(\mathrm{dd} / \mathrm{m})$ \\
\hline Choline & $3.19(\mathrm{~s}), 3.51(\mathrm{dd}), 4.06(\mathrm{~m})$ \\
\hline Ethanol & $1.17(\mathrm{t} / 7.1), 3.65(\mathrm{q})$ \\
\hline Formate & $8.44(s)$ \\
\hline Fructose & $3.55(\mathrm{~m}), 3.69(\mathrm{~m}), 3.82(\mathrm{~m}), 3.89(\mathrm{dd}), 3.99(\mathrm{~m}), 4.01(\mathrm{dd}), \mathbf{4 . 1 1}(\mathrm{m})$ \\
\hline Fumarate & $6.53(\mathrm{~s})$ \\
\hline Glucose & $3.23(\mathrm{dd}), 3.40(\mathrm{~m}), 3.46(\mathrm{~m}), 3.52(\mathrm{dd}), 3.70(\mathrm{t}), 3.72(\mathrm{~m}), 3.82(\mathrm{~m}), 3.89(\mathrm{dd}), 4.63(\mathrm{~d} / 8.0), 5.22(\mathrm{~d} / 3.7)$ \\
\hline Glutamate & $2.04(\mathrm{~m}), 2.12(\mathrm{~m}), 2.35(\mathrm{~m}), 3.75(\mathrm{dd})$ \\
\hline Glutamine & $2.13(\mathrm{~m}), 2.45(\mathrm{~m}), 3.77(\mathrm{t} / 6.1), 6.87(\mathrm{~s})$ \\
\hline Histidine & $3.21(\mathrm{dd}), 3.28(\mathrm{dd}), 4.01(\mathrm{dd}), 7.31(\mathrm{~s}), \mathbf{8 . 2 0}(\mathrm{s})$ \\
\hline Isoleucine & $0.93(\mathrm{t} / 7.4), 1.00(\mathrm{~d} / 7.0), 1.25(\mathrm{~m}), 1.46(\mathrm{~m}), 1.97(\mathrm{~m}), 3.66(\mathrm{~d})$ \\
\hline Leucine & $\mathbf{0 . 9 5}(\mathrm{t}), 1.70(\mathrm{~m}), 3.7(\mathrm{~m})$ \\
\hline Methanol & $3.35(\mathrm{~s})$ \\
\hline Methionine & $2.15(\mathrm{~m}), \mathbf{2 . 6 3}(\mathrm{t} / 7.5), 3.86(\mathrm{~m})$ \\
\hline myo-Inositol & $3.27(\mathrm{t} / 9.3), 3.52(\mathrm{dd}), 3.61(\mathrm{t} / 9.7), 4.06(\mathrm{t})$ \\
\hline Phenylalanine & $3.11(\mathrm{~m}), 7.32(\mathrm{~d} / 7.0), 7.37(\mathrm{~m}), 7.42(\mathrm{~m})$ \\
\hline Proline & $2.00(\mathrm{~m}), 2.06(\mathrm{~m}), 2.34(\mathrm{~m}), 3.33(\mathrm{~m}), 3.41(\mathrm{~m}), 4.12(\mathrm{dd})$ \\
\hline Sarcosine & $2.74(s), 3.60(s)$ \\
\hline Sucrose & $3.46(\mathrm{t} / 9.3), 3.55(\mathrm{dd}), 3.67(\mathrm{~s}), 3.75(\mathrm{t} / 9.5), 3.82(\mathrm{~m}), 3.82(\mathrm{~m}), 3.88(\mathrm{~m}), 4.04(\mathrm{t} / 8.6), 4.21(\mathrm{~d} / 8.7), 5.40(\mathrm{~d} / 3.9)$ \\
\hline Threonine & $1.32(\mathrm{~d} / 6.6), 3.58(\mathrm{~d} / 4.8), 4.25(\mathrm{~m})$ \\
\hline Trigonelline & $4.42(\mathrm{~s}), 8.07(\mathrm{~m}), 8.82(\mathrm{~m}), 9.11(\mathrm{~s})$ \\
\hline Tyrosine & $3.04(\mathrm{dd}), 3.19(\mathrm{dd}), 3.94(\mathrm{dd}), 6.89(\mathrm{~d}), \mathbf{7 . 1 8}(\mathrm{d})$ \\
\hline Valine & $\mathbf{0 . 9 8}(\mathrm{d} / 7.0), 1.03(\mathrm{~d} / 7.0), 2.26(\mathrm{~m}), 3.60(\mathrm{~d})$ \\
\hline Polyphenols* & $6.87(\mathrm{~s}), 7.60(\mathrm{~s})$ \\
\hline
\end{tabular}

a An asterisk (*) indicates tentative assignment.

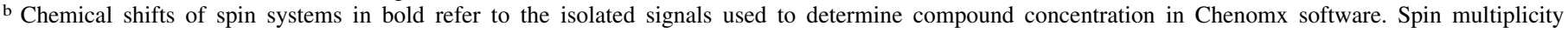
designations: $\mathrm{s}=$ singlet, $\mathrm{d}=$ doublet, $\mathrm{t}=$ triplet, $\mathrm{dd}=$ doublet of doublets, and $\mathrm{m}=$ complex multiplet. 
Interestingly, initial infection with either Phaeoacremonium minimum or Phaeomoniella chlamydospora seemed to diminish the negative impact of drought on plant growth (Fig. 2A), suggesting an interaction of fungal infection and drought tolerance. In fact, previous studies have shown that Phaeomoniella chlamydospora infection interferes with the grapevine response to water stress in a cultivar-dependent manner (Edwards et al. 2007b,c). In general, the impact of dual stresses on plants is less studied, and the consequences of combined stresses cannot be inferred from what is known about single-stress studies (Ramegowda and Senthil-Kumar 2014; Suzuki et al. 2014). The effects of simultaneous stresses on plants are complex, resulting in negative or positive effects of one stress over the other, and it has been documented that previous exposure to pathogen infection could result in tolerance to drought stress (Ramegowda and Senthil-Kumar 2014).

Our results did not show significant differences in the amount of chlorophyll a, chlorophyll b, and carotenoids, though their amount was consistently lower under water-stress conditions (Fig. 3). The larger difference was registered in Phaeomoniella chlamydosporainoculated plants, in which water-stressed vines presented significantly lower carotenoid concentration than normally watered plants, suggesting an effect of drought in the fungal infection. Damage to photosynthetic function has been shown as a consequence of both drought (Chaves et al. 2010; Escalona et al. 2003; Flexas et al. 1998, 2002; Maroco et al. 2002) and esca disease (Fontaine et al. 2016; Magnin-Robert et al. 2011; Petit et al. 2006). However, it has been reported that esca disease and drought affect photosynthetic systems through different means (Christen et al. 2007). In esca-diseased grapevines, a decrease of chlorophylls has been found but carotenoids have been reported to be not affected (Magnin-Robert et al. 2011; Petit et al. 2006). In our experiment, the lack of differences in the amount of photosynthetic pigments in response to fungal inoculation is likely due to the early infection stage.
Using ${ }^{1} \mathrm{H}-\mathrm{NMR}$ spectroscopy, we were able to identify, in a single analysis, 28 metabolites belonging to several chemical classes, including amino acids, sugars, salt or ester forms of carboxylic acids, alcohols, and other small molecules (Fig. 4; Table 1). This analytical technique has several advantages (namely, the fast sample preparation and the possibility of high-throughput) and has proven to be useful to the study of esca disease (Lima et al. 2010). Most of the compounds hereby identified have already been identified in grapevine xylem sap (Andersen and Brodbeck 1989; Peuke 2000; Roubelakis-Angelakis and Kliewer 1979) but, to the best of our knowledge, formate, fumarate, ethanol, methanol, choline, myo-inositol, sarcosine, and trigonelline are here being reported for the first time. Our results indicate that glutamine is the most abundant amino acid in grapevine xylem sap, which is in agreement with previous reports (Andersen and Brodbeck 1989; RoubelakisAngelakis and Kliewer 1979).

In general, the results showed a concentration increase of xylem sap components when grapevines were under water stress. This increase was more remarkable for amino acids, whereas sugar concentration only slightly increased. A noteworthy concentration increase was registered for asparagine, isoleucine, leucine, methionine, phenylalanine, proline, tyrosine, valine, sarcosine, and trigonelline (Table 2). The concentration increase of these metabolites in sap under water stress was even more significant when plants were infected with Phaeoacremonium minimum or Phaeomoniella chlamydospora (Figs. 5 and 6), which suggests an interaction between drought and esca-related fungal infection, even at an early infection stage. To the best of our knowledge, changes in grapevine xylem sap composition in response to drought have not been previously reported. Drought has been shown to induce modifications in the xylem sap composition of maize, sunflower, and castor bean, including increases in amino acids, organic acids, and phenylpropanoid compounds (Alvarez et al. 2008; Gollan et al.

TABLE 2. Concentration of metabolites observed in proton nuclear magnetic resonance spectra of grapevine xylem sap ${ }^{\mathrm{a}}$

\begin{tabular}{|c|c|c|c|c|c|c|c|c|c|}
\hline \multirow[b]{3}{*}{ Metabolite } & \multicolumn{3}{|c|}{ Mock (sterile water) } & \multicolumn{3}{|c|}{ Phaeoacremonium minimum } & \multicolumn{3}{|c|}{ Phaeomoniella chlamydospora } \\
\hline & \multicolumn{2}{|c|}{ Concentration $(\mathrm{mM})^{\mathrm{b}}$} & \multirow[b]{2}{*}{$\operatorname{Var}(\%)^{\mathrm{c}}$} & \multicolumn{2}{|c|}{ Concentration $(\mathrm{mM})^{\mathrm{b}}$} & \multirow[b]{2}{*}{$\operatorname{Var}(\%)^{\mathrm{c}}$} & \multicolumn{2}{|c|}{ Concentration $(\mathrm{mM})^{\mathrm{b}}$} & \multirow[b]{2}{*}{$\operatorname{Var}(\%)^{\mathrm{c}}$} \\
\hline & Nonwater stress & Water stress & & Nonwater stress & Water stress & & Nonwater stress & Water stress & \\
\hline 4-Aminobutyrate & $0.0488 \pm 0.006$ & $0.0504 \pm 0.006$ & 3 & $0.0315 \pm 0.002$ & $0.0400 \pm 0.004$ & 27 & $0.0498 \pm 0.009$ & $0.0581 \pm 0.004$ & 17 \\
\hline Alanine & $0.0157 \pm 0.005$ & $0.0082 \pm 0.001$ & -48 & $0.0045 \pm 0.001$ & $0.0056 \pm 0.001$ & 25 & $0.0111 \pm 0.004$ & $0.0095 \pm 0.001$ & -15 \\
\hline Arginine & $0.3737 \pm 0.043$ & $0.5904 \pm 0.066$ & $58 *$ & $0.3319 \pm 0.044$ & $0.4969 \pm 0.072$ & 50 & $0.3621 \pm 0.073$ & $0.6590 \pm 0.035$ & $82 *$ \\
\hline Asparagine & $0.0536 \pm 0.018$ & $0.1454 \pm 0.030$ & $171^{*}$ & $0.0374 \pm 0.007$ & $0.1873 \pm 0.033$ & $401 *$ & $0.0492 \pm 0.010$ & $0.1365 \pm 0.024$ & $177 *$ \\
\hline Aspartate & $0.0403 \pm 0.005$ & $0.0807 \pm 0.017$ & $100 *$ & $0.0311 \pm 0.005$ & $0.0458 \pm 0.012$ & 47 & $0.0333 \pm 0.005$ & $0.0809 \pm 0.011$ & $143^{*}$ \\
\hline Choline & $0.0066 \pm 0.001$ & $0.0072 \pm 0.001$ & 9 & $0.0051 \pm 0.000$ & $0.0056 \pm 0.001$ & 10 & $0.0058 \pm 0.001$ & $0.0074 \pm 0.000$ & 29 \\
\hline Ethanol & $0.2727 \pm 0.119$ & $0.3622 \pm 0.164$ & 33 & $0.4203 \pm 0.284$ & $0.3104 \pm 0.090$ & -26 & $0.2050 \pm 0.064$ & $0.1831 \pm 0.057$ & -11 \\
\hline Formate & $0.0171 \pm 0.004$ & $0.0110 \pm 0.001$ & -36 & $0.0191 \pm 0.003$ & $0.0117 \pm 0.004$ & -39 & $0.0138 \pm 0.002$ & $0.0158 \pm 0.003$ & 14 \\
\hline Fructose & $0.5588 \pm 0.088$ & $0.5570 \pm 0.054$ & 0 & $0.4756 \pm 0.077$ & $0.4184 \pm 0.096$ & -12 & $0.6403 \pm 0.108$ & $0.7136 \pm 0.102$ & 11 \\
\hline Fumarate & $0.0020 \pm 0.000$ & $0.0021 \pm 0.000$ & 4 & $0.0026 \pm 0.001$ & $0.0020 \pm 0.000$ & -23 & $0.0019 \pm 0.000$ & $0.0021 \pm 0.000$ & 12 \\
\hline Glucose & $0.6585 \pm 0.043$ & $1.0928 \pm 0.200$ & $66^{*}$ & $0.7481 \pm 0.090$ & $0.8709 \pm 0.116$ & 16 & $0.7737 \pm 0.091$ & $1.1254 \pm 0.086$ & 45 \\
\hline Glutamate & $0.0692 \pm 0.023$ & $0.0789 \pm 0.011$ & 14 & $0.0457 \pm 0.009$ & $0.0439 \pm 0.008$ & -4 & $0.0523 \pm 0.005$ & $0.0839 \pm 0.013$ & $61 *$ \\
\hline Glutamine & $3.0742 \pm 0.911$ & $6.1947 \pm 2.089$ & 102 & $2.4286 \pm 0.711$ & $2.8792 \pm 0.556$ & 19 & $3.2562 \pm 0.836$ & $5.8623 \pm 1.435$ & 80 \\
\hline Histidine & $0.0222 \pm 0.006$ & $0.0268 \pm 0.004$ & 21 & $0.0206 \pm 0.003$ & $0.0291 \pm 0.016$ & 41 & $0.0209 \pm 0.004$ & $0.0293 \pm 0.003$ & 40 \\
\hline Isoleucine & $0.0208 \pm 0.005$ & $0.0832 \pm 0.021$ & $300 *$ & $0.0148 \pm 0.002$ & $0.0681 \pm 0.011$ & $361 *$ & $0.0176 \pm 0.003$ & $0.0929 \pm 0.014$ & $427 *$ \\
\hline Leucine & $0.0232 \pm 0.006$ & $0.0661 \pm 0.017$ & 185 & $0.0143 \pm 0.002$ & $0.0537 \pm 0.012$ & $275^{*}$ & $0.0200 \pm 0.004$ & $0.0748 \pm 0.013$ & $274 *$ \\
\hline Methanol & $0.0081 \pm 0.002$ & $0.0070 \pm 0.000$ & -13 & $0.0055 \pm 0.001$ & $0.0051 \pm 0.000$ & -7 & $0.0058 \pm 0.001$ & $0.0072 \pm 0.000$ & 23 \\
\hline Methionine & $0.0137 \pm 0.002$ & $0.0363 \pm 0.010$ & $166^{*}$ & $0.0082 \pm 0.001$ & $0.0336 \pm 0.009$ & 310 & $0.0106 \pm 0.002$ & $0.0413 \pm 0.009$ & $291 *$ \\
\hline myo-Inositol & $0.0509 \pm 0.008$ & $0.0750 \pm 0.007$ & 47 & $0.0326 \pm 0.009$ & $0.0524 \pm 0.012$ & 61 & $0.0373 \pm 0.007$ & $0.0690 \pm 0.007$ & $85^{*}$ \\
\hline Phenylalanine & $0.0252 \pm 0.008$ & $0.0508 \pm 0.013$ & 102 & $0.0242 \pm 0.003$ & $0.0496 \pm 0.012$ & 105 & $0.0255 \pm 0.003$ & $0.0527 \pm 0.011$ & $107 *$ \\
\hline Proline & $0.0387 \pm 0.007$ & $0.1807 \pm 0.042$ & $367 *$ & $0.0251 \pm 0.003$ & $0.0754 \pm 0.024$ & 201 & $0.0368 \pm 0.013$ & $0.2002 \pm 0.043$ & $444 *$ \\
\hline Sarcosine & $0.0014 \pm 0.000$ & $0.0083 \pm 0.003$ & $500 *$ & $0.0008 \pm 0.000$ & $0.0051 \pm 0.001$ & $577 *$ & $0.0012 \pm 0.000$ & $0.0062 \pm 0.001$ & $399 *$ \\
\hline Sucrose & $0.3586 \pm 0.073$ & $0.6760 \pm 0.178$ & 88 & $0.1892 \pm 0.044$ & $0.2636 \pm 0.109$ & 39 & $0.1969 \pm 0.035$ & $0.5468 \pm 0.201$ & 178 \\
\hline Threonine & $0.0415 \pm 0.011$ & $0.0583 \pm 0.011$ & 40 & $0.0264 \pm 0.004$ & $0.0486 \pm 0.007$ & $84 *$ & $0.0322 \pm 0.006$ & $0.0677 \pm 0.008$ & $110^{*}$ \\
\hline Trigonelline & $0.0011 \pm 0.001$ & $0.0075 \pm 0.001$ & $560 *$ & $0.0005 \pm 0.001$ & $0.0052 \pm 0.001$ & $899 *$ & $0.0017 \pm 0.001$ & $0.0074 \pm 0.002$ & $351 *$ \\
\hline Tyrosine & $0.0054 \pm 0.002$ & $0.0138 \pm 0.002$ & $156^{*}$ & $0.0051 \pm 0.001$ & $0.0281 \pm 0.012$ & 449 & $0.0060 \pm 0.001$ & $0.0156 \pm 0.003$ & $160^{*}$ \\
\hline Valine & $0.0527 \pm 0.014$ & $0.0946 \pm 0.018$ & 80 & $0.0389 \pm 0.006$ & $0.0875 \pm 0.016$ & $125^{*}$ & $0.0499 \pm 0.011$ & $0.1110 \pm 0.014$ & $123^{*}$ \\
\hline
\end{tabular}

a Individual data provided in Supplementary Table S1.

b Average \pm standard error.

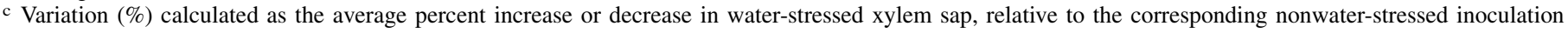
group. An asterisk (*) indicates concentration significantly different in water stress compared with nonwater stress $($ Mann-Whitney $U$ test, $P<0.05)$. 
1992; Goodger et al. 2005; Schurr and Schulze 1996). In grapevine, metabolite changes in response to drought have been studied in shoots, leaves, and berries, and also include increases in amino acids, organic acids, sugars, and polyphenols (Cramer et al. 2007; Griesser et al. 2015; Hochberg et al. 2013; Savoi et al. 2016). On the other hand, some studies have investigated modifications in grapevine xylem sap composition induced by xylem-inhabiting pathogens (Xylella fastidiosa and esca disease) but these studies focused only on phenolic compounds and fungal toxins, showing that the amount of these metabolites increases in xylem sap in response to infection, which is expected given the known role of phenolics in defense (Bruno and Sparapano 2006a, 2007; Bruno et al. 2007; Wallis and Chen 2012).

The compounds we report to be changed under water stress and fungal infection have been previously associated with plant response to both biotic or abiotic stress, suggesting that these
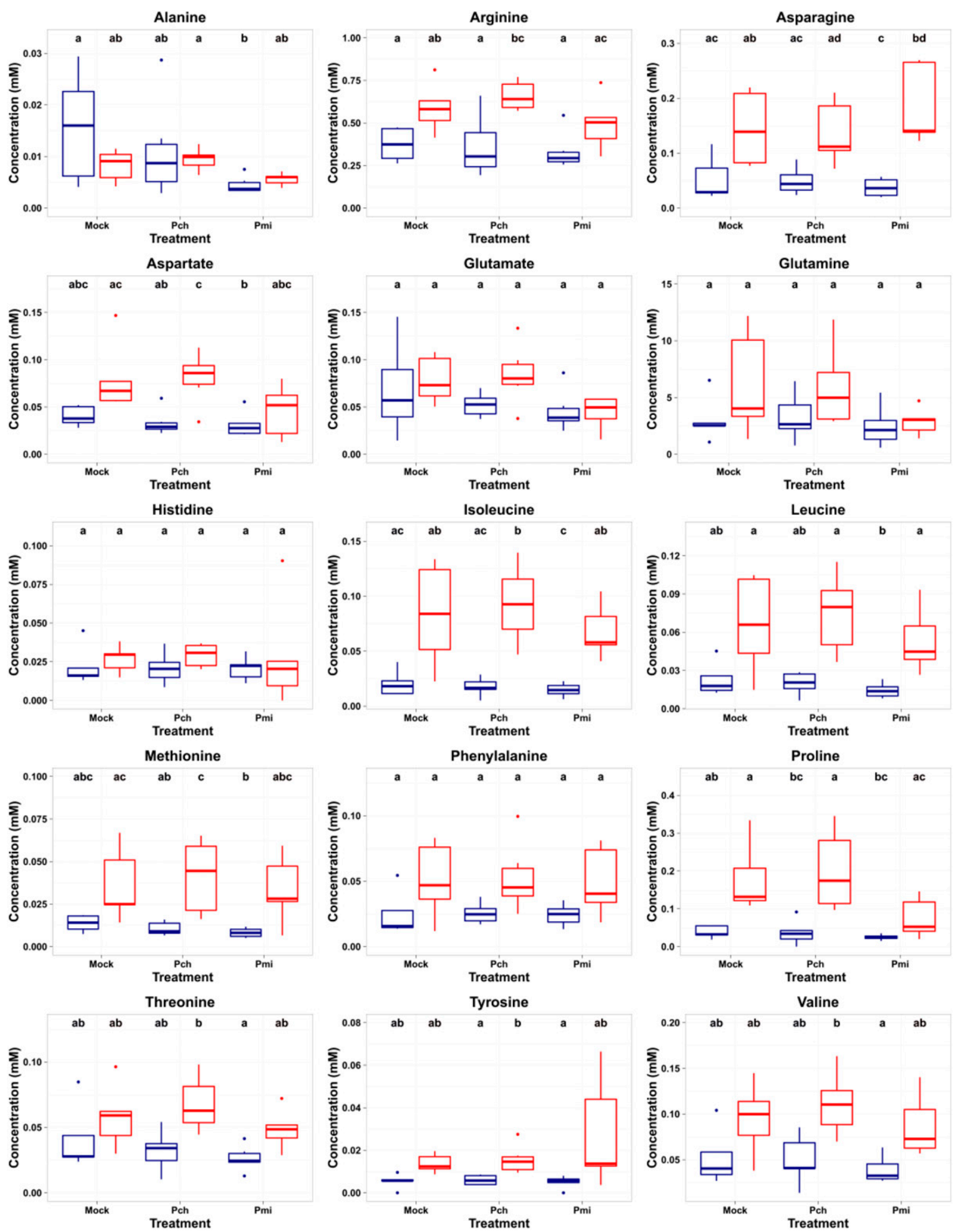

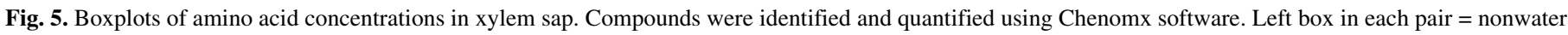

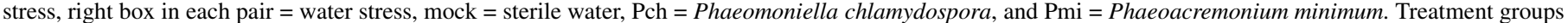
sharing the same letter are not significantly different (Kruskal-Wallis, Dunn's test with Bonferroni correction, $P<0.05$ ). 
compounds could play a role in tolerance or susceptibility to esca disease under water-stress conditions. Trigonelline has been shown to increase in response to oxidative, UV, and salt stresses, and has been proposed to act as an osmoregulator and to be an inducer of defense metabolism (Ashihara et al. 2015; Berglund 1994; Minorsky 2002; Tramontano and Jouve 1997). Sarcosine (also known as methylglycine, being a derivative of the amino acid glycine) has been found in root xylem sap and implicated in the physiological response of Cucurbita maxima to drought (Oda et al. 2005). Branched-chain amino acids (isoleucine, leucine, and valine), proline, and phenylalanine have been described to increase in response to water stress in several plants, including grapevine, and are considered to be associated with drought tolerance (Bowne et al. 2012; Hochberg et al. 2013; Semel et al. 2007; Witt et al. 2012). Interestingly, grapevines accumulating higher amount of amino acids associated with drought tolerance also showed enhanced accumulation of phytoalexins and exhibited lower susceptibility to Botrytis cinerea (Hatmi et al. 2015). Additionally, homeostasis of methionine has been implicated in the response to concomitant water and biotic stresses in Arabidopsis (Atkinson
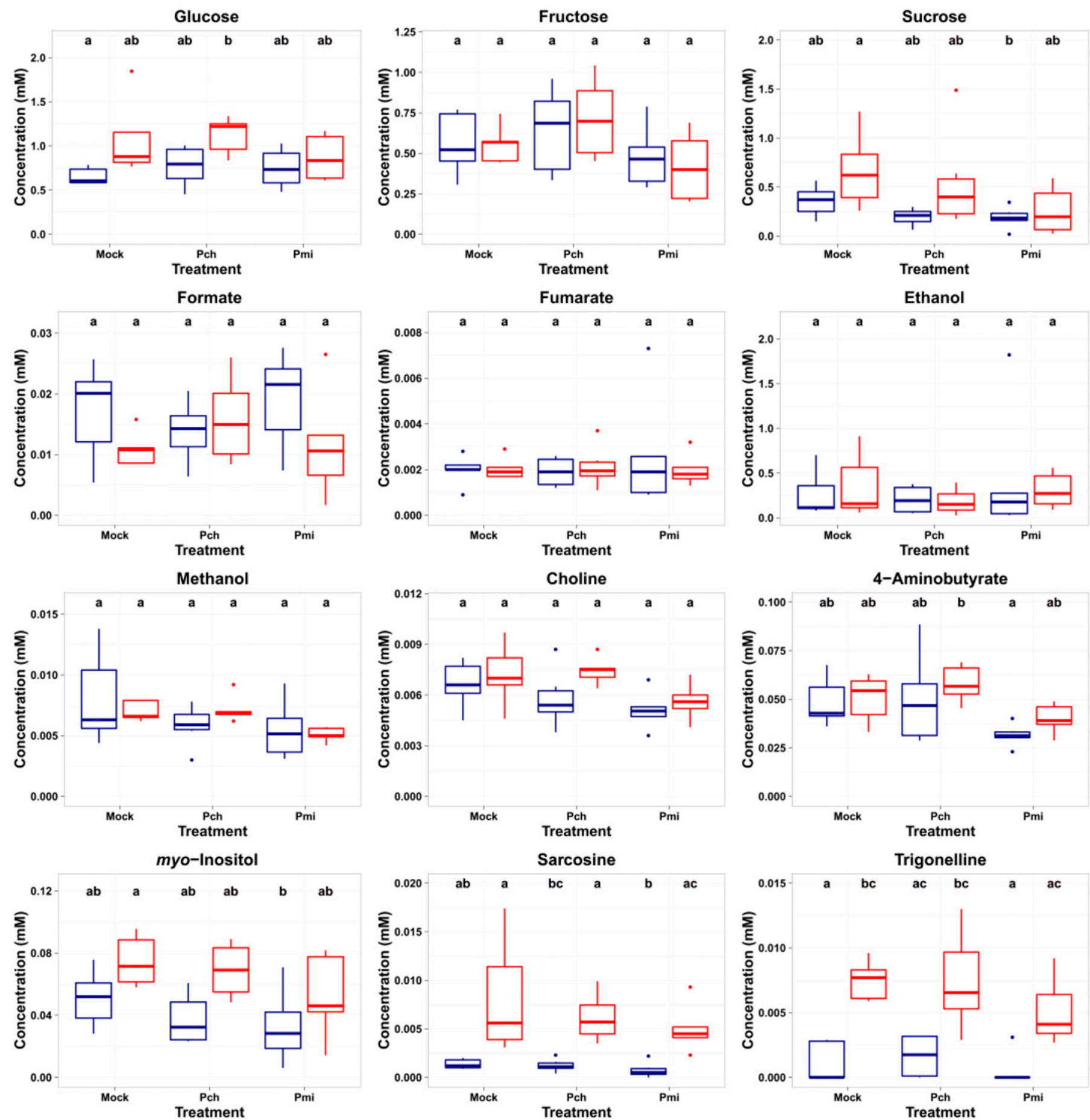

Fig. 6. Boxplots of sugar, organic acid, alcohol, and small molecule concentrations in xylem sap. Compounds were identified and quantified using Chenomx software. Left box in each pair nonwater stress, right box in each pair $=$ water stress, mock $=$ sterile water, Pch $=$ Phaeomoniella chlamydospora, and Pmi $=$ Phaeoacremonium minimum. Treatment groups sharing the same letter are not significantly different (Kruskal-Wallis, Dunn's test with Bonferroni correction, $P<0.05)$. 
et al. 2013). Our results suggest that drought's contribution to esca disease progression might be the increase of nutrient concentration in xylem sap. Higher nutrient availability could lead to increased fungal growth over time. This would be in agreement with previous observations that increased inoculum in the wood is associated with external symptom appearance (Magnin-Robert et al. 2014).

This experimental study adds further support to the suspected role of water stress in esca disease. Furthermore, it broadens the current knowledge about the plant metabolites that could be involved in esca disease. Because grapevines are traditionally managed without irrigation or under deficit irrigation (Chaves et al. 2010; Lovisolo et al. 2010), it is fundamental to understand the interaction between water stress and esca infection so that disease management practices can be improved. Furthermore, water stress has already been described to facilitate Pierce's disease, E. lata, and Botryosphaeriaceae spp. infection (Choi et al. 2013; McElrone et al. 2003; Sosnowski et al. 2011; van Niekerk et al. 2011). Nonetheless, it is likely that other factors influence the interaction of drought and esca infection, including the accumulation of defensive metabolites at critical infection stages. Further studies with more advanced infection stages and different levels of water stress are necessary to clarify the underlying mechanism by which drought predisposes grapevines to esca disease.

\section{ACKNOWLEDGMENTS}

We thank B. Addison (UCD NMR facility) for support in setting up NMR experiments, M. Zwieniecki (UCD Plant Sciences Department) for help setting up xylem sap extraction procedure, and UCD Foundation Plant Services for the donation of grapevine canes.

\section{LITERATURE CITED}

Abou-Mansour, E., Couche, E., and Tabacchi, R. 2004. Do fungal naphthalenones have a role in the development of esca symptoms? Phytopathol. Mediterr. 43:75-82.

Alvarez, S., Marsh, E. L., Schroeder, S. G., and Schachtman, D. P. 2008. Metabolomic and proteomic changes in the xylem sap of maize under drought. Plant Cell Environ. 31:325-340.

Amalfitano, C., Agrelli, D., Arrigo, A., Mugnai, L., Surico, G., and Evidente, A. 2011. Stilbene polyphenols in the brown red wood of Vitis vinifera cv. Sangiovese affected by "esca proper". Phytopathol. Mediterr. 50:S224-S235.

Amalfitano, C., Evidente, A., Surico, G., Tegli, S., Bertelli, E., and Mugnai, L. 2000. Phenols and stilbene polyphenols in the wood of esca-diseased grapevines. Phytopathol. Mediterr. 39:178-183.

Andersen, P. C., and Brodbeck, B. V. 1989. Chemical composition of xylem exudate from bleeding spurs of Vitis rotundifolia Noble and Vitis hybrid Suwannee in relation to pruning date. Am. J. Enol. Vitic. 40:155-160.

Andolfi, A., Mugnai, L., Luque, J., Surico, G., Cimmino, A., and Evidente, A. 2011. Phytotoxins produced by fungi associated with grapevine trunk diseases. Toxins (Basel) 3:1569-1605.

Ashihara, H., Ludwig, I. A., Katahira, R., Yokota, T., Fujimura, T., and Crozier, A. 2015. Trigonelline and related nicotinic acid metabolites: Occurrence, biosynthesis, taxonomic considerations, and their roles in planta and in human health. Phytochem. Rev. 14:765-798.

Atkinson, N. J., Lilley, C. J., and Urwin, P. E. 2013. Identification of genes involved in the response of Arabidopsis to simultaneous biotic and abiotic stresses. Plant Physiol. 162:2028-2041.

Ayres, P. G. 1984. The interaction between environmental stress injury and biotic disease physiology. Annu. Rev. Phytopathol. 22:53-75.

Berglund, T. 1994. Nicotinamide, a missing link in the early stress response in eukaryotic cells: A hypothesis with special reference to oxidative stress in plants. FEBS Lett. 351:145-149.

Bertsch, C., Ramírez-Suero, M., Magnin-Robert, M., Larignon, P., Chong, J., Abou-Mansour, E., Spagnolo, A., Clément, C., and Fontaine, F. 2013. Grapevine trunk diseases: Complex and still poorly understood. Plant Pathol. 62:243-265.

Bowne, J. B., Erwin, T. A., Juttner, J., Schnurbusch, T., Langridge, P., Bacic, A., and Roessner, U. 2012. Drought responses of leaf tissues from wheat cultivars of differing drought tolerance at the metabolite level. Mol. Plant 5:418-429.

Boyer, J. S. 1995. Biochemical and biophysical aspects of water deficits and the predisposition to disease. Annu. Rev. Phytopathol. 33:251-274.

Bruez, E., Baumgartner, K., Bastien, S., Travadon, R., Guérin-Dubrana, L., and Rey, P. 2016. Various fungal communities colonise the functional wood tissues of old grapevines externally free from grapevine trunk disease symptoms. Aust. J. Grape Wine Res. 22:288-295.

Bruez, E., Vallance, J., Gerbore, J., Lecomte, P., Da Costa, J. P., Guerin-Dubrana, L., and Rey, P. 2014. Analyses of the temporal dynamics of fungal communities colonizing the healthy wood tissues of esca leafsymptomatic and asymptomatic vines. PLoS One 9:e95928.

Bruno, G., and Sparapano, L. 2006a. Effects of three esca-associated fungi on Vitis vinifera L.: II. Characterization of biomolecules in xylem sap and leaves of healthy and diseased vines. Physiol. Mol. Plant Pathol. 69:195208.

Bruno, G., and Sparapano, L. 2006b. Effects of three esca-associated fungi on Vitis vinifera L.: I. Characterization of secondary metabolites in culture media and host responses to the pathogens in calli. Physiol. Mol. Plant Pathol. 69:209-223.

Bruno, G., and Sparapano, L. 2007. Effects of three esca-associated fungi on Vitis vinifera L.: V. Changes in the chemical and biological profile of xylem sap from diseased cv. Sangiovese vines. Physiol. Mol. Plant Pathol. 71:210-229.

Bruno, G., Sparapano, L., and Graniti, A. 2007. Effects of three escaassociated fungi on Vitis vinifera L.: IV. Diffusion through the xylem of metabolites produced by two tracheiphilous fungi in the woody tissue of grapevine leads to esca-like symptoms on leaves and berries. Physiol. Mol. Plant Pathol. 71:106-124.

Calzarano, F., Cichelli, A., and Odoardi, M. 2001. Preliminary evaluation of variations in composition induced by esca on cv. Trebbiano d'Abruzzo grapes and wines. Phytopathol. Mediterr. 40:S443-S448.

Calzarano, F., Seghetti, L., Del Carlo, M., and Cichelli, A. 2004. Effect of esca on the quality of berries, musts and wines. Phytopathol. Mediterr. 43: 125-135.

Chaves, M. M., Zarrouk, O., Francisco, R., Costa, J. M., Santos, T., Regalado, A. P., Rodrigues, M. L., and Lopes, C. M. 2010. Grapevine under deficit irrigation: Hints from physiological and molecular data. Ann. Bot. (Lond.) 105:661-676.

Choi, H. K., Iandolino, A., da Silva, F. G., and Cook, D. R. 2013. Water deficit modulates the response of Vitis vinifera to the Pierce's disease pathogen Xylella fastidiosa. Mol. Plant-Microbe Interact 26:643-657.

Christen, D., Schönmann, S., Jermini, M., Strasser, R. J., and Défago, G. 2007. Characterization and early detection of grapevine (Vitis vinifera) stress responses to esca disease by in situ chlorophyll fluorescence and comparison with drought stress. Environ. Exp. Bot. 60:504-514.

Cramer, G. R., Ergul, A., Grimplet, J., Tillett, R. L., Tattersall, E. A., Bohlman, M. C., Vincent, D., Sonderegger, J., Evans, J., Osborne, C., Quilici, D., Schlauch, K. A., Schooley, D. A., and Cushman, J. C. 2007. Water and salinity stress in grapevines: Early and late changes in transcript and metabolite profiles. Funct. Integr. Genomics 7:111-134.

Del Río, J. A., Gómez, P., Báidez, A., Fuster, M. D., Ortuño, A., and Frías, V. 2004. Phenolic compounds have a role in the defence mechanism protecting grapevine against the fungi involved in Petri disease. Phytopathol. Mediterr. 43:87-94.

Del Rio, J. A., Gonzalez, A., Fuster, M. D., Botia, J. M., Gomez, P., Frias, V., and Ortuño, A. 2001. Tylose formation and changes in phenolic compounds of grape roots Infected with Phaeomoniella chlamydospora and Phaeoacremonium species. Phytopathol. Mediterr. 40:S394-S399.

Edwards, J., Pascoe, I. G., and Salib, S. 2007a. Impairment of grapevine xylem function by Phaeomoniella chlamydospora infection is due to more than physical blockage of vessels with 'goo'. Phytopathol. Mediterr. 46:87-90.

Edwards, J., Salib, S., Thomson, F., and Pascoe, I. G. 2007b. The impact of Phaeomoniella chlamydospora infection on the grapevine's physiological response to water stress-Part 1: Zinfandel. Phytopathol. Mediterr. 46:26-37.

Edwards, J., Salib, S., Thomson, F., and Pascoe, I. G. 2007c. The impact of Phaeomoniella chlamydospora Infection on the grapevine's physiological response to water stress-Part 2: Cabernet Sauvignon and Chardonnay. Phytopathol. Mediterr. 46:38-49.

Escalona, J. M., Flexas, J., Bota, J., and Medrano, H. 2003. Distribution of leaf photosynthesis and transpiration within grapevine canopies under different drought conditions. Vitis 42:57-64.

Eskalen, A., Feliciano, A. J., and Gubler, W. D. 2007. Susceptibility of grapevine pruning wounds and symptom development in response to infection by Phaeoacremonium aleophilum and Phaeomoniella chlamydospora. Plant Dis. 91:1100-1104.

Evidente, A., Sparapano, L., Andolfi, A., and Bruno, G. 2000. Two naphthalenone pentaketides from liquid cultures of Phaeoacremonium aleophilum, a fungus associated with esca of grapevine. Phytopathol. Mediterr. 39: 162-168.

Feliciano, A. J., Eskalen, A., and Gubler, W. D. 2004. Differential susceptibility of three grapevine cultivars to Phaeomoniella chlamydospora in California. Phytopathol. Mediterr. 43:66-69.

Ferreira, J., van Wyk, P., and Calitz, F. 1999. Slow dieback of grapevine in South Africa-Stress-related predisposition of young vines for infection by Phaeoacremonium chlamydosporum. S. Afr. J. Enol. Vitic. 20:43-46. 
Fischer, M., and Kassemeyer, H. H. 2012. Water regime and its possible impact on expression of esca symptoms in Vitis vinifera: Growth characters and symptoms in the greenhouse after artificial infection with Phaeomoniella chlamydospora. Vitis 51:129-135.

Flexas, J., Bota, J., Escalona, J. M., Sampol, B., and Medrano, H. 2002. Effects of drought on photosynthesis in grapevines under field conditions: An evaluation of stomatal and mesophyll limitations. Funct. Plant Biol. 29:461-471.

Flexas, J., Escalona, J. M., and Medrano, H. 1998. Down-regulation of photosynthesis by drought under field conditions in grapevine leaves. Aust. J. Plant Physiol. 25:893-900.

Fontaine, F., Pinto, C., Vallet, J., Clément, C., Gomes, A. C., and Spagnolo, A. 2016. The effects of grapevine trunk diseases (GTDs) on vine physiology. Eur. J. Plant Pathol. 144:707-721.

Fox, J., and Weisberg, S. 2011. An R Companion to Applied Regression, 2nd ed. Sage, Thousand Oaks, CA.

Gollan, T., Schurr, U., and Schulze, E. D. 1992. Stomatal response to drying soil in relation to changes in the xylem sap composition of Helianthus annuus. I. The concentration of cations, anions, amino acids in, and $\mathrm{pH}$ of, the xylem sap. Plant Cell Environ. 15:551-559.

Gómez, P., Báidez, A. G., Ortuño, A., and Del Río, J. A. 2016. Grapevine xylem response to fungi involved in trunk diseases. Ann. Appl. Biol. 169: $116-124$

Goodger, J. Q., Sharp, R. E., Marsh, E. L., and Schachtman, D. P. 2005. Relationships between xylem sap constituents and leaf conductance of wellwatered and water-stressed maize across three xylem sap sampling techniques. J. Exp. Bot. 56:2389-2400.

Griesser, M., Weingart, G., Schoedl-Hummel, K., Neumann, N., Becker, M., Varmuza, K., Liebner, F., Schuhmacher, R., and Forneck, A. 2015. Severe drought stress is affecting selected primary metabolites, polyphenols, and volatile metabolites in grapevine leaves (Vitis vinifera cv. Pinot noir). Plant Physiol. Biochem. 88:17-26.

Hatmi, S., Gruau, C., Trotel-Aziz, P., Villaume, S., Rabenoelina, F., Baillieul, F., Eullaffroy, P., Clement, C., Ferchichi, A., and Aziz, A. 2015. Drought stress tolerance in grapevine involves activation of polyamine oxidation contributing to improved immune response and low susceptibility to $\mathrm{Bo}$ trytis cinerea. J. Exp. Bot. 66:775-787

Hochberg, U., Degu, A., Toubiana, D., Gendler, T., Nikoloski, Z., Rachmilevitch, S., and Fait, A. 2013. Metabolite profiling and network analysis reveal coordinated changes in grapevine water stress response. BMC Plant Biol. 13:184.

Hofstetter, V., Buyck, B., Croll, D., Viret, O., Couloux, A., and Gindro, K. 2012. What if esca disease of grapevine were not a fungal disease? Fungal Divers. 54:51-67.

Kuntzmann, P., Villaume, S., Larignon, P., and Bertsch, C. 2010. Esca, BDA and Eutypiosis: Foliar symptoms, trunk lesions and fungi observed in diseased vinestocks in two vineyards in Alsace. Vitis 49:71-76.

Larignon, P., and Dubos, B. 1997. Fungi associated with esca disease in grapevine. Eur. J. Plant Pathol. 103:147-157.

Letousey, P., Baillieul, F., Perrot, G., Rabenoelina, F., Boulay, M., Vaillant-Gaveau, N., Clement, C., and Fontaine, F. 2010. Early events prior to visual symptoms in the apoplectic form of grapevine esca disease. Phytopathology 100:424-431.

Lima, M. R., Diaz, S. O., Lamego, I., Grusak, M. A., Vasconcelos, M. W., and Gil, A. M. 2014. Nuclear magnetic resonance metabolomics of iron deficiency in soybean leaves. J. Proteome Res. 13:3075-3087.

Lima, M. R., Felgueiras, M. L., Graca, G., Rodrigues, J. E., Barros, A., Gil, A. M., and Dias, A. C. 2010. NMR metabolomics of esca disease-affected Vitis vinifera cv. Alvarinho leaves. J. Exp. Bot. 61:4033-4042.

Lima, M. R. M., Felgueiras, M. L., Cunha, A., Chicau, G., Ferreres, F., and Dias, A. C. P. 2017. Differential phenolic production in leaves of Vitis vinifera cv. Alvarinho affected with esca disease. Plant Physiol. Biochem. 112:45-52.

Lorrain, B., Ky, I., Pasquier, G., Jourdes, M., Dubrana, L. G., Gény, L., Rey, P., Donèche, B., and Teissedre, P. L. 2012. Effect of esca disease on the phenolic and sensory attributes of Cabernet Sauvignon grapes, musts and wines. Aust. J. Grape Wine Res. 18:64-72.

Lovisolo, C., Perrone, I., Carra, A., Ferrandino, A., Flexas, J., Medrano, H., and Schubert, A. 2010. Drought-induced changes in development and function of grapevine (Vitis spp.) organs and in their hydraulic and nonhydraulic interactions at the whole-plant level: A physiological and molecular update. Funct. Plant Biol. 37:98-116.

Magnin-Robert, M., Letousey, P., Spagnolo, A., Rabenoelina, F., Jacquens, L., Mercier, L., Clément, C., and Fontaine, F. 2011. Leaf stripe form of esca induces alteration of photosynthesis and defence reactions in presymptomatic leaves. Funct. Plant Biol. 38:856-866.

Magnin-Robert, M., Spagnolo, A., Alayi, T. D., Cilindre, C., Mercier, L., Schaeffer-Reiss, C., Van Dorsselaer, A., Clement, C., and Fontaine, F. 2014. Proteomic insights into changes in grapevine wood in response to esca proper and apoplexy. Phytopathol. Mediterr. 53:168-187.
Magnin-Robert, M., Spagnolo, A., Boulanger, A., Joyeux, C., Clement, C., Abou-Mansour, E., and Fontaine, F. 2016. Changes in plant metabolism and accumulation of fungal metabolites in response to esca proper and apoplexy expression in the whole grapevine. Phytopathology 106:541-553.

Marchi, G. 2001. Susceptibility to esca of various grapevine (Vitis vinifera) cultivars grafted on different rootstocks in a vineyard in the province of Siena (Italy). Phytopathol. Mediterr. 40:27-36.

Marchi, G., Peduto, F., Mugnai, L., Di Marco, S., Calzarano, F., and Surico, G. 2006. Some observations on the relationship of manifest and hidden esca to rainfall. Phytopathol. Mediterr. 45:S117-S126.

Maroco, J. P., Rodrigues, M. L., Lopes, C., and Chaves, M. M. 2002. Limitations to leaf photosynthesis in field-grown grapevine under drought-Metabolic and modelling approaches. Funct. Plant Biol. 29:451-459.

McElrone, A. J., Sherald, J. L., and Forseth, I. N. 2003. Interactive effects of water stress and xylem-limited bacterial infection on the water relations of a host vine. J. Exp. Bot. 54:419-430.

Minorsky, P. V. 2002. Trigonelline: A diverse regulator in plants. Plant Physiol. 128:7-8.

Mugnai, L., Graniti, A., and Surico, G. 1999. Esca (black measles) and brown wood-streaking: Two old and elusive diseases of grapevines. Plant Dis. 83: 404-418.

Oda, A., Shimizu, M., Kuroha, T., and Satoh, S. 2005. Induction of xylem sap methylglycine by a drought and rewatering treatment and its inhibitory effects on the growth and development of plant organs. Physiol. Plant. 124: 515-523.

Petit, A. N., Vaillant, N., Boulay, M., Clement, C., and Fontaine, F. 2006. Alteration of photosynthesis in grapevines affected by esca. Phytopathology 96:1060-1066.

Peuke, A. D. 2000. The chemical composition of xylem sap in Vitis vinifera $\mathrm{L}$. cv. Riesling during vegetative growth on three different Franconian vineyard soils and as influenced by nitrogen fertilizer. Am. J. Enol. Vitic. 51: 329-339.

Ramegowda, V., and Senthil-Kumar, M. 2014. The interactive effects of simultaneous biotic and abiotic stresses on plants: Mechanistic understanding from drought and pathogen combination. J. Plant Physiol. 176C:47-54.

R Core Team. 2015. R: A Language and Environment for Statistical Computing. R Foundation for Statistical Computing, Vienna.

Roubelakis-Angelakis, K. A., and Kliewer, W. M. 1979. The composition of bleeding sap from Thompson seedless grapevines as affected by nitrogen fertilization. Am. J. Enol. Vitic. 30:14-18.

Savoi, S., Wong, D. C. J., Arapitsas, P., Miculan, M., Bucchetti, B., Peterlunger, E., Fait, A., Mattivi, F., and Castellarin, S. D. 2016. Transcriptome and metabolite profiling reveals that prolonged drought modulates the phenylpropanoid and terpenoid pathway in white grapes (Vitis vinifera L.). BMC Plant Biol. 16:67.

Schoeneweiss, D. F. 1978. Water stress as a predisposing factor in plant disease. Pages 61-99 in: Water Deficits and Plant Growth, Vol. 5. T. T. Kozlowski, ed. Academic Press, New York.

Schoeneweiss, D. F. 1981. The role of environmental stress in diseases of woody plants. Plant Dis. 65:308-314.

Schultz, H. R., and Matthews, M. A. 1988. Resistance to water transport in shoots of Vitis vinifera L.- Relation to growth at low water potential. Plant Physiol. 88:718-724.

Schurr, U., and Schulze, E. D. 1996. Effects of drought on nutrient and ABA transport in Ricinus communis. Plant Cell Environ. 19:665-674.

Secchi, F., and Zwieniecki, M. A. 2012. Analysis of xylem sap from functional (nonembolized) and nonfunctional (embolized) vessels of Populus nigra: Chemistry of refilling. Plant Physiol. 160:955-964.

Semel, Y., Schauer, N., Roessner, U., Zamir, D., and Fernie, A. R. 2007. Metabolite analysis for the comparison of irrigated and non-irrigated field grown tomato of varying genotype. Metabolomics 3:289-295.

Sims, D. A., and Gamon, J. A. 2002. Relationships between leaf pigment content and spectral reflectance across a wide range of species, leaf structures and developmental stages. Remote Sens. Environ. 81:337-354.

Sosnowski, M. R., Luque, J., Loschiavo, A. P., Martos, S., Garcia-Figueres, F., Wicks, T. J., and Scott, E. S. 2011. Studies on the effect of water and temperature stress on grapevines inoculated with Eutypa lata. Phytopathol. Mediterr. 50:S127-S138.

Stevens, R. M., Harvey, G., and Aspinall, D. 1995. Grapevine growth of shoots and fruit linearly correlate with water stress indices based on root-weighted soil matric potential. Aust. J. Grape Wine Res. 1:58-66.

Surico, G., Marchi, G., Braccini, P., and Mugnai, L. 2000. Epidemiology of esca in some vineyards in Tuscany (Italy). Phytopathol. Mediterr. 39:190-205.

Surico, G., Mugnai, L., and Marchi, G. 2006. Older and more recent observations on esca: A critical overview. Phytopathol. Mediterr. 45:S68-S86.

Suzuki, N., Rivero, R. M., Shulaev, V., Blumwald, E., and Mittler, R. 2014. Abiotic and biotic stress combinations. New Phytol. 203:32-43.

Tabacchi, R., Fkyerat, A., Poliart, C., and Dubin, G. 2000. Phytotoxins from fungi of esca of grapevine. Phytopathol. Mediterr. 39:156-161. 
Tramontano, W. A., and Jouve, D. 1997. Trigonelline accumulation in saltstressed legumes and the role of other osmoregulators as cell cycle control agents. Phytochemistry 44:1037-1040.

Valtaud, C., Thibault, F., Larignon, P., Bertsch, C., Fleurat-Lessard, P., and Bourbouloux, A. 2011. Systemic damage in leaf metabolism caused by esca infection in grapevines. Aust. J. Grape Wine Res. 17:101-110.

van Niekerk, J. M., Strever, A. E., du Toit, P. G., Halleen, F., and Fourie, P. H. 2011. Influence of water stress on Botryosphaeriaceae disease expression in grapevines. Phytopathol. Mediterr. 50:S151-S165.

Wallis, C. M., and Chen, J. 2012. Grapevine phenolic compounds in xylem sap and tissues are significantly altered during infection by Xylella fastidiosa. Phytopathology 102:816-826.

White, T. J., Bruns, T., Lee, S., and Taylor, J. W. 1990. Amplification and direct sequencing of fungal ribosomal RNA genes for phylogenetics. Pages 315-322 in: PCR Protocols: A Guide to Methods and Applications. M. A. Innis, D. H. Gelfand, J. J. Sninsky, and T. J. White, eds. Academic Press, Inc., New York.
Wickham, H. 2009. ggplot2: Elegant Graphics for Data Analysis. Springer, New York.

Wickham, H. 2011. The split-apply-combine strategy for data analysis. J. Stat. Softw. 40:1-29.

Wishart, D. S., Jewison, T., Guo, A. C., Wilson, M., Knox, C., Liu, Y., Djoumbou, Y., Mandal, R., Aziat, F., Dong, E., Bouatra, S., Sinelnikov, I., Arndt, D., Xia, J., Liu, P., Yallou, F., Bjorndahl, T., Perez-Pineiro, R., Eisner, R., Allen, F., Neveu, V., Greiner, R., and Scalbert, A. 2013. HMDB 3.0-The Human Metabolome Database in 2013. Nucleic Acids Res. 41: D801-D807.

Witt, S., Galicia, L., Lisec, J., Cairns, J., Tiessen, A., Araus, J. L., Palacios-Rojas, N., and Fernie, A. R. 2012. Metabolic and phenotypic responses of greenhouse-grown maize hybrids to experimentally controlled drought stress. Mol. Plant 5:401-417.

Yadeta, K. A., and Thomma, B. 2013. The xylem as battleground for plant hosts and vascular wilt pathogens. Front. Plant Sci. 4:97. 